\title{
Feeding behaviour in a 'basal' tortoise provides insights on the transitional feeding mode at the dawn of modern land turtle evolution
}

Nikolay Natchev, Nikolay Tzankov, Ingmar Werneburg, Egon Heiss

Almost all extant testudinids are highly associated with terrestrial habitats and the few tortoises with high affinity to aquatic environments are found within the genus Manouria. Manouria belongs to a clade which forms a sister taxon to all remaining tortoises and is suitable as a model for studying evolutionary transitions within modern turtles. We analysed the feeding behaviour of Manouria emys and due to its phylogenetic position, we hypothesise that the species might have retained some ancestral features associated with an aquatic lifestyle. We tested whether $M$. emys is able to feed both in aquatic and terrestrial environments. In fact, $M$. emys repetitively tried to reach submerged food items in water, but always failed to grasp them - no suction feeding mechanism was applied. When feeding on land, M. emys showed another peculiar behaviour; it grasped food items by its jaws - a behaviour typical for aquatic or semiaquatic turtles - and not by the tongue as generally accepted as the typical feeding mode in all tortoises studied so far. $\ln M$. emys, the hyolingual complex remained retracted during all food uptake sequences, but the food transport was entirely lingual based. The kinematical profiles significantly differed from those described for other tortoises and from those proposed from the general models on the function of the feeding systems in lower tetrapods. We conclude that the feeding behaviour of $M$. emys might reflect a remnant of the primordial condition expected in the aquatic ancestor of the tortoises. 
1 Feeding behaviour in a 'basal' tortoise provides insights on the transitional feeding mode at

2 the dawn of modern land turtle evolution

3

4 Abbreviated title: Feeding behaviour in Manouria emys

5

6 Nikolay Natchev ${ }^{1,2}$, Nikolay Tzankov ${ }^{3}$, Ingmar Werneburg ${ }^{4,5}$, Egon Heiss ${ }^{6}$

$8 \quad{ }^{1}$ Department of Integrative Zoology, Vienna University, Althanstrasse 14, 1090 Vienna, Austria

$9 \quad{ }^{2}$ Faculty of Natural Science, Shumen University, Universitetska 115, 9700 Shumen, Bulgaria

$10{ }^{3}$ Section Vertebrates, National Museum of Natural History, Bulgarian Academy of Sciences,

11 Tzar Osvoboditel 1, 1000 Sofia, Bulgaria

$12{ }^{4}$ Museum für Naturkunde, Leibniz-Institut für Evolutions- \& Biodiversitätsforschung an der

13 Humboldt-Universität zu Berlin, Invalidenstraße 43, 10115 Berlin, Germany

$14{ }^{5}$ Institut für Biologie, Humboldt-Universität zu Berlin, Philippstr. 13, 10115 Berlin, Germany

$15{ }^{6}$ Institute of Systematic Zoology and Evolutionary Biology, Friedrich-Schiller-University Jena,

16 Erbertstr. 1, 07743 Jena, Germany 
INTRODUCTION

Comprising more than 180 species, the cryptodiran taxon Testudinoidea represents the most diverse group of extant turtles (e.g., Fritz and Havaš, 2007; Thomson and Shaffer, 2010).

21 Traditionally, it contains three major extant groups, including the emydids, the geoemydids and 22 the testudinids (tortoises) (Fig. 1). All molecular phylogenetic studies (Iverson et al., 2007; Shaffer, 2009; Thomson and Shaffer, 2010; Barley et al., 2010) confirm a sister group relationship of the testudinids and the geoemydids (Fig. 1). The relationship of Platysternidae to other turtle groups remains unresolved (Parham et al. 2006), but most molecular studies support a closer relationship to emydids (e.g., Thomson and Shaffer, 2010; Crawford et al., 2015). Palaeontological studies have shown that all testudinoids share aquatic ancestors, from which terrestrial species evolved (Danilov, 1999; Sukhanov, 2000; Joyce and Gauthier, 2004).

The majority of the Triassic stem turtles were terrestrial as indicated by the design and proportions of the limbs, which were adapted for terrestrial locomotion (for a comprehensive discussion see Joyce, 2015). With the emergence of modern turtles (Testudines) during the Jurassic period (e.g., Danilov and Parham, 2006; Sterli, 2010; Sterli and de la Fuente, 2011), a general transition of turtles into an aquatic environment occurred (Willis et al., 2013). The invasion of aquatic environments induced diversification into several subgroups (see Joyce, 2007; Thomson and Shaffer, 2010). Due to the different physical properties (drag, viscosity, etc.) of air and water, the new environment required morphological and functional adaptations of the

37 locomotion- and feeding system to enable efficient swimming behaviour and aquatic food uptake 38 (i.e. suction feeding) (Schumacher, 1973; Lemell et al., 2002).

The sister group of all remaining Testudinoidea is the diverse and possibly paraphyletic 40 extinct taxon $\dagger$ Lindholmemydidae (Fig. 1; Lourenço et al., 2012), which contains genera such as 
$†$ Mongolemys and †Lindholmemys (Danilov, 1999; Joyce and Gauthier, 2004). Some poorly documented aquatic taxa such as $\dagger$ Haichemydidae and the $\dagger$ Sinochelyidae may perhaps also belong to $\dagger$ Lindholmemydidae. This group was recorded from aquatic sediments of the late Early Cretaceous and apparently had an amphibious lifestyle (Sukhanov, 2000). Among recent cryptodirans, semi-aquatic to semi-terrestrial lifestyle is typical for most emydids (plus platysternids) and geoemydids, as well as for some kinosternids (see Depecker et al., 2006, but also Nakajima et al., 2014). The remaining extant species are entirely terrestrial (tortoises), or predominantly aquatic (see Joyce and Gauthier, 2004; Rasmussen et al., 2011).

Among modern turtles, a transition from an aquatic to a semi-terrestrial or fully terrestrial habitat and the capacity to exploit terrestrial food sources has evolved independently within all three major testudinoid lineages (for overview see Summers et al., 1998; Natchev et al., 2009). At least eight emydid species are able to feed on land as well as under water (see Bels et al., 1997, 2008; Summers et al., 1998; Stayton, 2011). During terrestrial feeding, such amphibious emydids use their jaws to grasp food items (jaw prehension). Similarly, all amphibious geoemydids studied to date also use jaw prehension in terrestrial food uptake (see Heiss et al., 2008; Natchev et al., 2009). In contrast, all testudinids studied so far use the tongue to touch the food items, a behaviour referred to as "lingual prehension" (see Wochesländer et al., 1999; Bels et al., 2008). According to Bels et al. (2008), lingual prehension is obligatory for all tortoises.

The tortoises show a clear tendency towards herbivory and emancipation from water as living and feeding medium (see Pritchard, 1979; Ernst and Barbour, 1989; Bonin et al., 2006). In fact, testudinids seem to have lost their ancestral ability to feed under water and exclusively rely on terrestrial trophic ecologies. Some predominantly terrestrial geoemydids are able to complete the whole feeding process on land and under water (Natchev et al., 2010). Similarly, testudinids 
64 with tendencies towards an amphibious lifestyle might have retained the ancestral skill to feed 65 underwater. Hence, information on bimodal feeding mechanisms in tortoises is of great 66 importance to understand the evolution of terrestrial feeding mechanisms and subsequent 67 evolution of the predominantly terrestrial lifestyle in tortoises.

68 The genus Manouria, being of the most 'basal' extant tortoises with a strong association to 69 aquatic environments (Høybye-Mortensen, 2004; Stanford et al., 2015), constitutes a suitable 70 model to study the feeding mechanisms in testudinids. Its partially aquatic feeding habit 71 purported to be associated with the observed morphological extension of the palatines onto the 72 triturating surface of the upper jaw (character 30 sensu Gerlach, 2001), a diagnostic feature common to geoemydid turtles. Another geoemydid-like feature is the unique existence of class II mental glands (Winokur and Legler, 1975).

The present study was conceived to provide a detailed analysis of the feeding behaviour in a species of the genus Manouria. Manouria emys is found in close association with water. Hence, we 77 designed experiments to reveal whether this species is able to complete the entire feeding process under both aquatic and terrestrial conditions as some geoemydids do (see Natchev et al., 2009, 2010). tongue. The hyoid complex is predominantly cartilaginous (Heiss et al., 2011). On the base of

82 the specific morphology of the feeding apparatus (elastic basis of the oropharynx and 83 voluminous lingual structures) we suggest a poor suction feeding performance in case Manouria 84 attempts to feed under water.

85 Wochesländer et al. $(1999,2000)$ and Bels et al. (2008) stated that the feeding kinematics in 86 all testudinids involve two common features: an obligatory lingual prehension and the split of the 
87 gape cycle in four main phases: slow open phase I (SOI); slow open phase II (SOII); fast open 88 phase (FO); fast close phase (FC). In our experiments we test whether these kinematical 89 elements are present in the feeding behaviour of M. emys. On the base of our findings, we fine90 tune the kinematical feeding models proposed for tortoises. The gained new data require a re91 evaluation of the concept on the function of the tongue in the food uptake in tortoises. Having in 92 mind the phylogenetical position of $M$. emys and the specifics of its feeding behaviour, we 93 propose hypothesis on the evolution of the terrestrial feeding among testudinoids in particular 94 and turtles in general. We discuss also on the interrelationship between the diet and the feeding 95 media in the course of turtle's evolution.

97 MATERIALS AND METHODS

\section{Ecological background}

100 Both extant species of Manouria, the Asian forest tortoise M. emys and the impressed tortoise M. impressa, have a restricted distribution in Southeast Asia. M. emys has a narrow distribution in Bangladesh, India (Assam, Meghalaya, Mizoram, Nagaland), Myanmar, Thailand, Malaysia (East and West), and Indonesia (Kalimantan, Sumatra). The nominate subspecies, $M$. emys emys - the subject of this study, inhabits the southern part of the species range (Fritz and Havaš, 2007; TTWG, 2014, Stanford et al., 2015). moisture. It is commonly found reposing in wet areas, buried in mud or under the leaf litter where it may spend long periods of time. It is active even during rainy weather. Direct sun 
110 nocturnal lifestyle (Ernst, Altenburg, and Barbour, 2000; Vetter and Daubner, 2000, Stanford et 111 al., 2015).

112 According to the available literature, the diet of $M$. emys includes plants, fungi,

113 invertebrates, and frogs (Nutphand, 1979; Das, 1995; Lambert and Howes, 1994, Høybye-

114 Mortensen, 2004). It has been reported to feed on plants in shallow mountain streams (Nutphand, 115 1979).

117 Experimental setting

118 Animal husbandry and experiments were in strict accordance with the Austrian Protection of

119 Animals Act. The animals used in the present study were obtained commercially and kept at $12 \mathrm{~h}$

120 dark/light cycles in a large terrarium $(150 \times 100 \mathrm{~cm}$ ground area) with a permanently filtered

121 water basin and spacious terrestrial area. The turtles were fed different fruits, vegetables,

122 commercially obtained tortoise pellets, dead mice, as well as pieces of cattle heart and liver,

123 offered on the terrestrial part of the terrarium. Carapace lengths in the three subadult

124 experimental animals ranged between 109-135 mm with body masses between 234-236 g. For

125 filming terrestrial feeding, the specimens were put in a dry glass cuvette $(24 \times 60 \times 30 \mathrm{~cm})$. When

126 the food was offered on the floor of the cuvette, the tortoises often twisted their necks and rotated

127 their heads in attempt to grasp the food item. The side movements made the filming of the

128 animals in strict lateral view very difficult and the landmarks were not clearly visible during the

129 sequence. By the use of forceps for food display we completely eliminated these problems and

130 were able to shoot perfect lateral plans of the feeding turtles. The food in the feeding

131 experiments was offered at a position which was similar to the position on which we offered the

132 food in the terrarium where the tortoises were housed. The animals did not extend vastly their 
133 necks to reach the food items (see Supplements). The position of the offered food was

134 completely "natural". The tortoises needed to stretch their necks forwards rather than

135 downwards, which did not impacted other kinematic patterns of the feeding cycles.

136 As food items we used small pieces of cattle heart measuring approximately $5 \times 5 \times 5 \mathrm{~mm}$.

137 The turtles were filmed from lateral aspect (with a reference grid $1 \mathrm{x} 1 \mathrm{~cm}$ in the background) via

138 the digital high-speed camera system Photron Fastcam-X 1024 PCI (Photron limited; Tokyo,

139 Japan) at 500 fps with a highly light-sensitive objective AF Zoom - Nikkor 24-85 mm (f/2,8-4D

140 IF). Two "Dedocool Coolh" tungsten light heads with $2 \times 250 \mathrm{~W}$ (ELC), supplied by a

141 "Dedocool COOLT3" transformer control unit (Dedo Weigert Film GmbH; München, Germany)

142 were used for illumination. We filmed and analysed the food uptake and the food transport

143 cycles in eight feeding sequences for each specimen.

144 The setting for filming aquatic feeding of submerged food comprised the experimental

145 aquarium filled with water to a level of $3 \mathrm{~cm}$ and presentation of food items in front of the

146 turtle's snout. In order to reduce the light intensity and for optimisation of the digitising process,

147 the frame rate was reduced to $250 \mathrm{fps}$. As the tortoises were unable to grasp the food item in a

148 total of 36 trials, the kinematics of the feeding apparatus had been analysed (see below) in nine

149 selected representative feeding trials.

150 For both terrestrial and "aquatic feeding" sequences, horizontal (X-axis) and vertical (Y-

151 axis) coordinates of relevant landmarks (see Fig. 2) were digitised frame by frame using "SIMI-

152 MatchiX" (SIMI Reality Motion Systems; Unterschleißheim, Germany). Based on the

153 displacement of the markers, we were able to calculate the gape amplitude (distance between the

154 tip of the upper and lower beak), head movement (distance between the anterior tip of the

155 carapace and the point "P" on Fig. 2), tongue movements (distance between the most ventral 
156 point on tympanum and the tip of the tongue when visible), and hyoid movements (distance

157 between the point "P" on Fig. 2 and the basis of the posterior ceratobranchial). To compare the

158 kinematic feeding pattern of $M$. emys to those of other studied turtles and to understand the

159 coordination between the elements of the feeding apparatus, these data were used for calculation

160 of the following kinematical variables: duration of Slow open phase (SO); duration of Slow open

161 phases I and II (SOI and SOII) when present; duration of fast open (FO); duration of maximum

162 gape phase (MG); duration of fast close (FC); time to peak gape (TPG); total cycle duration

163 (TCD); duration of hyoid protraction (HyDD); duration of hyoid retraction (HyVD); duration of

164 the total hyoid cycle (THC); hyoid retraction velocity (HyRV); duration of head protraction

165 (HP); duration of head retraction (HR); duration of tongue protraction (TP); tongue retraction

166 velocity; delay of the start of hyoid retraction relative to the tongue retraction start; delay of

167 reaching peak gape relative to start of the hyoid retraction; delay of reaching peak gape relative

168 to tongue retraction start (see Table 1).

169

$170 \quad$ Statistics

171 We tested for any differences among the frequency of occurrences of defined patterns both in

172 food uptake (FU) and food transport (T), i.e. sequences with: missing split of the jaw opening in

173 SO and FO; without detectable split of discrete SOI and SOII slow gape phase; lacking MG

174 phase. In order to provide the comparisons, Chi-square test with Yates' correction was

175 performed. Then we tested for possible existence of differentiation in kinematical variables in

176 both feeding stages (FU and T). All variables were tested with the Shapiro-Wilk test for normal

177 distribution. When the $\mathrm{p}$-value was less than the chosen alpha level $(\mathrm{p}<0.05)$, the null hypothesis

178 was rejected and data were excluded from further analyses. In addition, all variables included in 
179 Table 1 were tested with Levene's and Brown-Forsythe tests and then processed with Welch's

180 ANOVA for heteroscedastic data. Tukey's honest significant difference test (HSD) was

181 performed for post-hoc analyses when applicable.

182 Furthermore, in order to express the degree of individual differentiation among the studied

183 specimens, a Canonical discriminant analysis (CDA) was performed. Standard descriptive

184 statistics including mean, range, standard deviation [(SD) and confidential interval at 95\% CI]

185 were presented.

186

187 RESULTS

188

189

When feeding on land, the Asian forest tortoises always grasped food by the jaws. After

190

food uptake, one to four transport cycles followed prior to oesophageal packing (see Schwenk,

191 2000). The tip of the tongue was barely visible during food uptake (see Fig. 3b-c) indicating that

192 the tongue was not protracted. By contrast, during transport cycles, the cyclic movements of the

193 tongue were well visible as it was rhythmically pro- and retracted to transport the food item

194 towards the oesophagus (Fig. 5).

195 When trying to feed under water (Fig. 4), M. emys submerged its head under the water level

196 and protruded the gaping jaws toward the food item. The gape cycle was newer split in slow and

197 fast jaw open phases. The tongue tip was not visible from the lateral aspect and the hyolingual

198 complex did not protract prior reaching peak gape. No retraction of the hyoid complex was

199 detected prior jaw closure. The gape cycle duration exceeded one and a half seconds and was

$2001.94 \pm 0.36 \mathrm{~s}$ (mean $\pm \mathrm{SD}$ ). Despite the unsuccessful attempts, the turtles repeatedly tried to catch 
201 the submerged food. In several events, we were able to detect that the food item was carried 202 away by the bow wave induced by jaw closing.

203 The variables of the kinematical profiles are summarised in Table 1. In the statistic tests, we 204 found highly significant differences in sequences with and without both SO I and SO II when 205 food uptake and transport stages were compared $\left(\chi_{(1, N=98)}^{2}=25.05, p<0.001\right)$. Similarly 206 significant differences were observed when comparing food uptake and transport cycles in 207 respect to sequences with and without slow jaw open phases as well as with and without 208 maintaining jaw maximum gape - MG phase $\left(\chi_{(1, \mathrm{~N}=98)}^{2}=6.10, \mathrm{p}=0.02 ; \chi_{(1, \mathrm{~N}=98)}^{2}=6.52, \mathrm{p}=0.01\right)$.

209 Nine of the variables which describe the food uptake process were detected to show 210 significant differences between individuals (Table 1). In transport cycles, six out of 18 variables 211 differed significantly amongst individuals (see Table 1)., Seven out of nine variables differed 212 significantly when testing for differences between grasping and transport cycles: fast jaw open 213 duration (FO; $F_{\text {Welch (1,43) }}=15.17, p=0.011$ ); maximum gape $\left(\mathrm{MG} ; \mathrm{F}_{\text {Welch }(1,26)}=15.89, \mathrm{p}=0.001\right)$; 214 fast closing $\left(\mathrm{FC} ; \mathrm{F}_{\text {Welch }(1,26)}=7.86, \mathrm{p}=0.010\right)$; time to peak gape (TPG; $\mathrm{F}_{\text {Welch }(1,72)}=46.78$, $215 \mathrm{p}<0.001)$; total gape cycle duration $\left(\mathrm{TCD} ; \mathrm{F}_{\mathrm{Welch}(1,72)}=52.50, \mathrm{p}<0.001\right)$; head protraction duration $216\left(\mathrm{HP} ; \mathrm{F}_{\mathrm{Welch}(1,67)}=52.23, \mathrm{p}<0.001\right)$; and head retraction duration $\left(\mathrm{HR} ; \mathrm{F}_{\mathrm{Welch}(1,47)}=12.57, \mathrm{p}=0.002\right)$.

217 When comparing three further parameters among the transport cycles in all three specimens 218 (delay of HyVD start relative to TR start; delays of TPG relative to HyVD; delay of TPG relative 219 to TR starts), statistically significant differences were found among all compared pairs $220 \quad\left(\mathrm{~F}_{\mathrm{Welch}(2,105)}=41.58, \mathrm{p}<0.001\right)$.

221 The performed canonical discriminant analysis (CDA) revealed the existence of substantial 222 degree of individualism among the studied specimens (Fig. 7). However, only the first axis 223 eigenvalue exceeded the level of acceptance, i.e. 1. First axis explained $70 \%$ of the total 
224 variance. Among the 18 studied variables only two (THC and HPR) showed higher correlation

225 scores than 0.75 . On the base of the CDA and the detected degree of individualism mentioned

226 above, we can conclude that the patterns displayed by the studied specimens can be regarded as

227 similar but not as uniform.

228

229 DISCUSSION

230

The Asian forest tortoise repetitively tried to feed on dispersed food items under water, 232 which was an unexpected and hitherto unknown behaviour among tortoises. However, M. emys always failed to consume the submerged food. On land, M. emys grasped food with the jaws, just

234 like all known aquatic or semiterrestrial turtles do, but not with the tongue as formerly predicted 235 for all tortoises. On the basis of our results we discuss several important evolutionary, 236 behavioural, and functional aspects.

237

\section{Evolution of food uptake among turtles}

239 In general, most aquatic turtles combine a fast acceleration of the head towards the food or 240 prey item and a suction feeding mechanism is induced by fast oropharyngeal volume expansion.

241 In some extant turtles, a strong suction flow can be generated and prey is directly sucked into the 242 oropharynx without contact with the jaws [e.g., Chelus fimbriatus (Lemell et al., 2002), Apalone 243 spinifera (Anderson, 2009), Pelodiscus sinensis (N.N. and I.W. unpublished data)]. However,

244 most extant turtles cannot generate such strong suction flows and only compensate ("gulp") the

245 bow wave that otherwise would push small to moderately sized food items away from the fast

246 approaching head. Such species finally fix and grasp prey with the jaws (see Lauder and 
247 Prendergrast, 1992; Lemell et al., 2000; Aerts et al., 2001, Natchev et al., 2009, 2011). We 248 consider the latter as plesiomorphic behaviour for extant turtles.

249 Among extant turtles, the ability to complete the whole feeding process (including food 250 uptake, food manipulation and transport, esophageal packing, and swallowing) on land has been 251 tested and documented for only six species so far. All of them were members of Testudinoidea

252 (Fig. 1; see also Summers et al., 1998; Bels et al., 2008; Natchev et al., 2009). The terrestrial 253 mode of food uptake differs dramatically among and within the three testudinoid subgroups (see

254 Bels et al., 1997, 2008; Summers et al., 1998; Wochesländer et al., 1999; Natchev et al., 2009, 255 present study). Correspondingly, it appears as if terrestrial feeding re-evolved several times 256 independently amongst turtles. Unfortunately, only limited experimental data are available on 257 feeding mechanisms in emydids and geoemydids. Further functional and palaeontological 258 investigations may help to sort out the issues on the evolution of the feeding behaviour and the 259 morphology of the feeding apparatus in testudinoids.

260 Very limited information is available on feeding mechanisms employed by amphibious non261 testudinoid turtles that occasionally exploit terrestrial food sources. Weisgram (1985 a,b) 262 documented a kinosternid (Claudius angustatus) that caught prey on land and dragged it into 263 water for transport and swallowing. Natchev et al. (2008) documented another kinosternid 264 (Sternotherus odoratus) catching food on land, but failing to transport it through the oropharynx. 265 Among extant turtles, successful food transport on land seems to be restricted to testudinoids. 266 The development of enlarged and muscular tongues within this group (von Bayern, 1884; 267 Werneburg, 2011) represents adaptation to improved terrestrial food manipulation.

268 Based on experimental data, Natchev et al. (2009) described and summarised three 269 categories of terrestrial food uptake modes among Testudinoidae: (A) Jaw prehension with 
270 retracted hyolingual complex, as observed in the geoemydid genus Cuora (Natchev et al., 2009);

271 (B) Jaw prehension with slightly protracted hyolingual complex, as observed in emydids (Bels et

272 al., 1997; Stayton, 2011); (C) Lingual prehension - the tongue touches the food item prior to food

273 uptake, as documented in all tortoises studied so far (Wochesländer et al. 1999, Bels et al. 2008).

274 The food uptake mode of $M$. emys, however, differs substantially from that of all remaining

275 tortoises (category C). In fact, the hyolingual complex in M. emys remained fully retracted

276 during the food prehension on land, and the first contact with the food item was by the jaws.

277 Accordingly, the feeding mechanism of M. emys should be assigned to category A, along with

278 that of semi-aquatic geoemydids.

279 We now aim to construct a theoretical scenario on the evolution of terrestrial feeding 280 mechanisms in turtles. Given the aquatic origin of all living turtles, the functional transition from 281 aquatic to terrestrial feeding mechanisms could hypothetically have involved four stages, 282 beginning with an exclusively aquatic feeding ancestor. In different lineages and stages, turtles 283 may have left their aquatic environments for various reasons e.g. for exploiting new food niches.

284 The species that retained predominantly aquatic life styles may grasp food by the jaws on land, 285 but have to drag it into the water for further intraoral (hydrodynamic based) transport. In recent 286 turtles, such behaviour was documented in the kinosternids C. angustatus (Weisgram, $1985 \mathrm{a}, \mathrm{b}$ ) 287 and Sternotherus odoratus (Natchev et al., 2011), as well as in the emydid Trachemys scripta 288 (Weisgram, 1985 b; Weisgram et al., 1989) and other emydids (see Stayton, 2011). Turtles of the 289 second hypothetical evolutionary stage grasped food by the jaws, while the tongue was used for 290 intraoral food transport on land. Such species would still have retained their underwater feeding 291 ability by using hydrodynamic mechanisms. When grasping food on land, the tongue remained 292 retracted or was protracted without however touching the food item. Among extant turtles, such a 
293 feeding mode is found in the geoemydid genus Cuora (Heiss et al., 2008; Natchev et al., 2009,

294 Natchev et al., 2010) and in some emydids (Bels et al., 1997; Summers et al., 1998, Stayton, 295 2011). In the next theoretical evolutionary step (stage three), behavioural and morphological 296 adaptations for terrestrial feeding were further advanced, increasing the efficiency of terrestrial 297 food transport at the expense of the ability to use effective hydrodynamic mechanisms in water. 298 Such species still grasped food items with their jaws on land (as typical for aquatic or 299 semiaquatic turtles), but were no longer able to take up dispersed food if submerged, which 300 features prominently in the present case of M. emys. Finally, in a fourth stage, turtles became 301 fully terrestrial and their tongue was obligatorily involved in food uptake as documented in the 302 tortoises Testudo (Eurotestudo) hermanni boettgeri (Weisgram, 1985 b; Wochesländer et al., 303 1999), Kinixis belliana, Geochelone elephantopus and G. radiata (Bels et al., 2008).

304 Our investigations demonstrate that the 'basal' tortoise M. emys does not contact food with 305 the tongue prior to jaw prehension on land. This shows that tongue to food contact is 306 characteristic of advanced tortoises only. We consider the terrestrial feeding behaviour of $M$. 307 emys as plesiomorphic and potentially inherited from its semiaquatic ancestors. On that base, $M$. 308 emys can be considered a transitional turtle in regard to secondary terrestriality.

309 We propose that hyolingual protrusion evolved in the lineage forming to advanced tortoises 310 (Fig. 1). Manouria emys has a large tongue with massive intrinsic and extrinsic musculature (see 311 Heiss et al., 2011). The advanced and complex lingual musculo-skeletal architecture allows the 312 turtle to protrude the tongue outside the margins of the rhamphothecae (see Fig. 2). However, $M$. 313 emys does not use lingual food prehension as typical for all other tortoises studied so far. In fact,

314 it seems that the Manouria [and perhaps Gopherus (N.N. personal observations)] "lineage" has

315 retained the jaw prehension mechanism inherited from earlier aquatic ancestors. It seems that the 
316 tortoises, in general, evolved fleshy tongues which improve the food transport performance. The

317 advanced tortoises only refined the behaviour of food uptake on land via lingual food contact

318 prior to jaw closure (see Wochesländer et al., 1999; Bels et al., 2008).

319

320

Function of the protruded tongue in the testudinid's food uptake

321

What would be the potential advantage of the obligatory lingual protrusion, found in the 322 more derived tortoises? One possible explanation is that the tongue is used as a prehensile organ

323 for food ingestion analogous to that found in other tetrapod groups (for overview see Schwenk,

324 2000; Schwenk and Wagner, 2001). However, for tortoises such interpretation might be put into 325 question. By examining all published data available (Wochesländer et al., 1999; Bels et al., 326 2008), we were not able to find any convincing evidence that tortoises collect food with their 327 tongues - they just touch it. In all published feeding sequences, the contact between the food and 328 the tongue is clearly demonstrated - yet, in all cases, after the initial contact of the tongue with 329 the food, the head moves forward and the food item is not dragged into the mouth by tongue 330 retraction, but is grasped by the jaws during the fast jaw closing (FC gape phase). Initial food 331 ingestion in tortoises might not be considered "lingual prehension" (see Schwenk, 2000; Bels et 332 al., 2008) in the strict sense, but should be regarded as "jaw prehension following lingual 333 contact". This prompts the question: why is an obligatory contact of the tongue to the food 334 present in extant tortoises (except in Manouria and also conceivably in Gopherus) during food 335 uptake? In other words: why do tortoises apply a more complex and presumably more 336 energetically expensive food uptake mechanism by including movements of the hyolingual 337 complex in addition to the movements of the neck and jaws alone? 
We propose that the lingual contact provides tactile information on the position of the food

339 item and helps the advanced tortoises to compensate the "information gap" which occurs when

340 the food is approached to a distance where it is out of sight. The eyes of tortoises are positioned

341 laterally on the head (Pritchard, 1979) and the turtles are not able to permanently observe the

342 position of the food item when the neck is protracted and the gape is positioned around it. The

343 prolonged maximum gape (MG) phase found in most ingestion cycles of $M$. emys (see Table 1,

344 Figure 3 and Figure 6) might be the result of lack of lingual contact with the food surface. In all

345 published sequences and kinematical profiles on food uptake in tortoises, there is a clear

346 tendency toward a split of the gape cycle into slow open (SO) and fast open (FO) gape phases

347 (see Wochesländer, 1999; Bels et al., 2008). The lack of tongue protrusion might explain the lack

348 of slow open (SO) and fast open (FO) split in the gape cycle of food uptake in the geoemydid

349 Cuora (see Natchev et al., 2009). In most food uptakes analysed in M. emys, SO phases are not

350 present and the gape increases gradually (see Table 1 and Figure 6). Similar as in Cuora, the lack

351 of SO phases might be explained by the lack of tongue protrusion in food uptake (see Natchev et

352 al., 2009).

353

354 Intraoral food transport on land

355 The execution of the transport cycles require coordination of the activities of contractile

356 elements such as the jaw opening and closing muscles, head protracting and retracting muscles,

357 intrinsic and extrinsic lingual muscles, as well as muscles that protract and retract the hyolingual

358 complex as a whole unit (Jones et al., 2012; Werneburg, 2011, 2013). In contrast to this

359 complicated choreography, the mode of food prehension in M. emys suggests less complex

360 neuromotoric coordination between neck and jaw movements. Yet, the execution of the transport 
361 cycles is often more than twice shorter in duration (see Table 1). A possible explanation for the

362 longer duration of food uptake cycles relative to transport cycles might be that during transport,

363 the coordination centres of the muscle activities execution are permanently supplied with

364 information concerning the position of the food item within the oropharynx and the proper

365 movements can be executed precisely in a shorter time.

366 In his work on the feeding mechanisms in domestic animals, Bels (2006) established that a

367 pre-programmed Generalise Cyclic Model (GCM) - very similar to those proposed from

368 Bramble and Wake (1985) - is universally valid among the different groups of tetrapods,. The

369 feeding kinematics of the Asian forest tortoise differs in some aspects from those proposed by

370 the GCM. The kinematics of the feeding system in M. emys seems to be pre-programmed, but

371 under permanent feed-back control. The values of the gape and hyoid/hyolingual cycle patterns

372 in the three specimens studied here show high degrees of variation, both concerning food uptake

373 and food transport (see Table 1 and Figures 5-7). The slow open phases (SO) are not obligatory.

374 The gape cycle often includes a phase of retaining maximum gape (see Table 1, Figure 3, 5). In

375 turtles, the maximum gape phase (MG) was described for the gape cycle in Cuora sp. (Natchev

376 et al., 2009, 2010) and was confirmed for kinostrnids (Natchev et al., 2011). The presence of a

377 prolonged maximum gape phase (MG) can be easily overlooked when the frame rate of the film

378 sequence is not high enough (i.e., step between successive frames over 10 milliseconds). Thus, it

379 may be present in other turtles but was not taken into account by the calculations of the

380 kinematical profile (see Stayton, 2011; Nischizawa et al., 2014).

381 The GCM presupposes that the start of hyoid retraction coincides with the start of fast open

382 phase (FO). However, our calculations (see Table 1 and Figure 5) demonstrate that in M. emys

383 the hyoid retraction in the food transport cycle starts shortly prior reaching peak gape. The same 
384 pattern was detected by the investigation of aquatic, semi-aquatic, but also predominantly

385 terrestrial cryptodirans (Natchev et al., 2008, 2009, 2010, 2011).

386

387 Relations between the habitat preferences and the diet in turtles

388 In the evolution of the testudinids there is a clear shift not only in the habitat preferences

389 (from aquatic to terrestrial), but corresponding shifts are also seen in dietary preferences. In that

390 taxon it manifests in a tendency toward herbivory. Most of the recent tortoises rely on diets

391 mainly composed of plant material (for overview see Pritchard, 1979; Ernst et al., 2000; Bonin et

392 al., 2006). The partly carnivorous lifestyle of Manouria sp. (Bonin et al., 2006) may be a relic of

393 the carnivorous diet of the ancestor of the tortoises and supports the transitional status of the

394 genus.

395 Apparently the feeding media (air vs. water) and the dietary shift had a large influence on

396 the overall feeding behaviour of the testudinids (see Bels et al., 2008). The suction mechanism

397 was lost and replaced by a jaw food prehension system (this study) or by "lingual prehension"

398 (Wochesländer et al., 1999; Bels et al., 2008). Probably, the switch to herbivory determined the

399 reorganisations in the morphology of the jaw muscle system and the proportions of the skull in

400 tortoises (see Werneburg 2011, 2012, 2013). By feeding predominantly on plants (immobile

401 items), the tortoises may prolong the duration of the food uptake cycles and have more time to

402 adjust their prehension kinematics to every single feeding situation.

403 We propose that the habitat preferences and the diet change in turtles are firmly correlated

404 (e.g. Bels et al., 2008; Werneburg, 2014). The overall rigid design of the turtle 'body plan'

405 hinder the animals to actively hunt for agile prey in terrestrial environments (King, 1996). We

406 hypothesise that this statement is also valid for the terrestrial stem turtles and that these animals 
407 were predominantly herbivorous (sensu King, 1996). In aquatic turtles, in contrast, the buoyancy

408 of the water overrides the shell-caused restrictions of mobility and also suction feeding can be

409 applied for carnivorous feeding. Those advantages might have been the key factor for the turtles

410 to become aquatic (and carnivorous) in the Jurassic. There may be several reasons for the

411 secondary terrestriality in tortoises and presumably one of the main was the inter- and

412 intraspecific concurrence for food resources.

413

\section{CONCLUSIONS}

415

416 We propose that the ancestral food uptake mode in tortoises was jaw based when feeding on

417 land. During the shift from aquatic to terrestrial lifestyle, including a shift from aquatic to 418 terrestrial feeding biology, the Manouria (and most likely also Gopherus) "lineage" had retained

419 pure jaw prehension in food uptake. The hyolingual complex in that lineage exhibits the typical 420 morphological features of tortoises that feed exclusively on land (see Bramble, 1973; Winokur,

421 1988; Heiss et al., 2011), such as an enlarged fleshy tongue with abundant papillae, a complex 422 tongue musculature, a relatively small and mainly cartilaginous hyoid and hypoglossum. The 423 evolutionary shift in the morphology of the hyolingual complex was apparently primed by the 424 optimisation of the food transport behaviour and not for food uptake. We suggest that the 425 involvement of the tongue during food uptake found in the derived extant tortoises serves as a 426 tactile sensory tool for the localisation of the food item prior to jaw prehension. Thus, the tongue 427 is not used as the main food collecting organ in modern tortoises and the food uptake mode 428 represents a derived jaw prehension system. 


\section{ACKNOWLEDGEMENTS}

431

432 We would like to thank Josef Weisgram, Andreas Wanninger, Patrick Lemell, Christian 433 Beisser and Thomas Schwaha (Department for Integrative Zoology, University of Vienna) for 434 providing material and suggestions for the executions of our experiments. Alexander 435 Westerström contributed sorely to the revision of our manuscript. Stefan Kummer, Katherina 436 Singer, Monika Lintner and Marion Hüffel are acknowledged for the careful housing of the 437 animals. The reviewers provided helpful comments and suggestions to improve our paper. The 438 study was funded by the FWF Austrian Science Fund, Project no. P20094-B17 on which E.H. 439 and N.N. were employed and the Advanced Postdoc Mobility fund P300P3_158526 of the Swiss 440 National Science Foundation granted to I.W.

441 


\section{REFERENCES}

445

446

447

448

449

450

451

452

453

454

455

456

457

458

459

460

461

462

463

464

Aerts P, Van Damme J, Herrel A. 2001. Intrinsic mechanics and control of fast cranio-cervical movements in aquatic feeding turtles. American Zoologist 41:1299-1310.

Anderson NJ. 2009. Biomechanics of feeding and neck motion in the softshell turtle, Apalone spinifera. Rafinesque. D. A. USA: Idaho State University. P. 89.

Barley A J, Spinks R C, Thomson, Shaffer HB. 2010. Fourteen nuclear genes provide phylogenetic resolution for difficult nodes in the turtle tree of life. Molecular Phylogenetics and Evolution 55:1189-1194.

von Bayern L F. 1884. Zur Anatomie der Zunge - eine vergleichend-anatomische Studie. München, Literarisch-Artistische Anstalt (Theodor Riedel).

Bels VL, Davenport J, Delheusy V. 1997. Kinematic analysis of the feeding behaviour in the box turtle Terrapene carolina (L.), (Reptilia: Emydidae). Journal of Experimental Zoology 277:198-212.

Bels VL. 2006. Feeding in domestic vertebrates - from structure to behaviour. UK: CABI Publishing

Bels VL, Baussart S, Davenport J, Shorten M, O`Riordan RM, Renous S, Davenport J. 2008. Functional Evolution of feeding behaviour in turtles. In: Wyneken J, Godfrey MH, Bels V, eds. Biology of turtles. USA: CRC Press Taylor \& Francis Group. p. 189-212.

Bonin F, Devaux B, Dupre A. 2006. Turtles of the world. Translated by Pritchard PCH. UK, Baltimore: Johns Hopkins University Press. 
465 Bramble DM. 1973. Media dependent feeding in turtles. American Zoologist 13:1342.

466 Bramble DM, Wake DB. 1985. Feeding Mechanisms of Lower Tetrapods. In: Hildebrand M, 467 Bramble DM, Liem KF, Wake DB, eds. Functional Vertebrate Morphology 13. 468 Massachusetts and London, England: Harvard University Press Cambridge. p. 230-261.

469 Crawford NG, Parham JF, Sellas AB, Faircloth BC, Glenn TC, Papenfuss TJ, Henderson JB, 470 Hansen MH, Simison WB. 2015. A phylogenomic analysis of turtles. Molecular $471 \quad$ Phylogenetics and Evolution 83:250-257

472 Danilov I. 1999. A new lindholmemydid genus (Testudines: Lindholmemydidae) from the mid473 Cretaceous of Uzbekistan. Russian Journal of Herpetology 6(1):63-71.

474

475

476

477

478

479

480 481 Washington, D.C.

482 Ernst CH, Altenburg RGM, Barbour RW. 2000. Turtles of the World. World Biodiversity 483 484

485 Gerlach J. 2001. Tortoise phylogeny and the 'Geochelone' problem. Phelsuma, suppl. A. 9:1486

Danilov I, Parham JF. 2006. A redescription of 'Plesiochelys' tatsuensis from the Late Jurassic of China, with comments on the antiquity of the crown clade Cryptodira. Journal of Vertebrate Paleontology. 26(3):573-580.

Das I. 1995. Turtles and tortoise of India. Bombay, India: Oxford University Press. p. 179.

Depeker M, Berge C, Penin X, Renous S. 2006. Geometric morphometrics of the shoulder gridle in extant turtles (Chelonii). Journal of Anatomy 208: 35-45.

Ernst, C.H., Barbour, R.W., 1989. Turtles of the World. Smithsonian Institution Press, Database, CD-ROM Series, Windows, Version 1.2. Amsterdam: Biodiversity Center of ETI. Fritz U, Havaš P. 2007. Checklist of chelonians of the world. Vertebrate Zoology 57(2):149-368. 24. 
487 Iverson J, Brown BRM, Akre TS, Near TJ, Le M, Thomson RC, Starkey DE. 2007). In search of 488 the tree of life for turtles. Chelonian Research Monographs 4:85-106.

489 Heiss E, Plenk H, Weisgram J. 2008. Microanatomy of the Palatal Mucosa of the Semiaquatic 490 Malayan Box Turtle, Cuora amboinensis, and Functional Implications. Anatomical records $491 \quad 291(7): 876-885$.

492 Heiss E, Natchev N, Schwaha T, Salaberger D, Lemell P, Beisser C, Weisgram J. 2011. 493 Oropharyngeal Morphology in the Basal Tortoise Manouria emys emys With Comments on 494 Form and Function of the Testudinid Tongue. Journal of Morphology 272:1217-1229.

495

496

498

499

500

501

502 503

504 505

506 King G. 1996. Reptiles and herbivory. Chapman \& Hall. London

Høybye-Mortensen K, 2004, The tortoise Manouria emys emys: behaviour and habitat in the wild. M. Sc. Thesis, University of South Denmark. p 100.

Jones MEH, Werneburg I, Curtis N, Penrose R, O’Higgins P, Fagan MJ, Evans SE. 2012. The head and neck anatomy of sea turtles (Cryptodira: Chelonioidea) and skull shape in Testudines. PLOS ONE 7(11):e47852.

Joyce WG. 2007. Phylogenetic relationships of Mesozoic turtles. Bulletin of the Peabody Museum for Natural History 48(1):3-102.

Joyce WG. 2015 (in press). The origin of turtles: a paleontological perspective. Journal of Experimental Zoology, Part B, Molecular and Developmental Evolution

Joyce WG, Gauthier JA .2004. Palaeoecology of Triassic stem turtles sheds new light on turtle origins. Proceedings of the Royal Society London Series B - Biological Sciences 271:1-5. 
507 Lambert FR, Howes JR. 1994. Ranging, breeding behaviour and food of Asian brown 508 tortoise Manouria emys in Borneo. Malayan Nature Journal 48:125-131.

509 Lauder GV, Prendergast T. 1992. Kinematics of aquatic prey capture in the snapping turtle 510 Chelydra serpentina. Journal of Experimental Biology 164:55-78.

511 Lemell P, Beisser CJ, Weisgram J. 2000. Morphology and function of the feeding apparatus of 512 Pelusios castaneus (Chelonia; Pleurodira). Journal of Morphology 244:127-135.

513 Lemell P, Lemell C, Snelderwaard P, Gumpenberger M, Wochesländer R, Weisgram J. 2002.

514 Feeding patterns of Chelus fimbriatus (Pleurodira: Chelidae). Journal of Experimental 515 Biology 205:1495-1506.

516 Lourenço JM, Claude J, Galtier N, Chiari Y. 2012. Dating cryptodiran nodes: Origin and 517 diversification of the turtle superfamily Testudinoidea. Molecular Phylogeny and Evolution $518 \quad 62: 496-507$.

519 Nakajima Y, Hirayama R, Endo H, 2014. Turtle humeral microanatomy and its 520 relationshipto lifestyle. Biological Journal of the Linnean Society, 112: 719-734.

521 Natchev N, Heiss E, Lemell P, Weisgram J. 2008. Kinematic analysis of prey capture, prey 522 transport and swallowing in the Common Musk Turtle Sternotherus odoratus (Chelonia, 523 Kinosternidae). Comparative Biochemistry and Physipology Part A vol. 150:95.

524 Natchev N, Heiss E, Lemell P, Stratev D, Weisgram J. 2009. Analysis of prey capture and food 525 transport kinematics in two Asian box turtles, Cuora amboinensis and Cuora flavomarginata 526 (Chelonia, Geoemydidae), with emphasis on terrestrial feeding patterns. Zoology 112:113$527 \quad 127$ 
528 Natchev N, Lemell P, Heiss E, Beisser C, Weisgram J. 2010. Aquatic feeding in a terrestrial

529 turtle: a functional-morphological study of the feeding apparatus in the Indochinese box

530 turtle Cuora galbinifrons (Testudines, Geoemydidae). Zoomorphology 129:111-119.

531 Natchev N, Heiss E, Singer K, Kummer S, Salaberger D, Weisgram J. 2011. Structure and 532 Function of the Feeding Apparatus in the Common Musk Turtle Sternotherus odoratus 533 (Chelonia, Kinosternidae). Contributions to Zoology 80:143-156.

534 Nishizawa H, Tabata R, Hori T, Mitamura H, Arai N. 2014. Feeding kinematics of freshwater 535 turtles: what advantage do invasive species possess? Zoology 117: 315-318.

536 Nutphand W. 1979. The Turtles of Thailnad. Thailand: Siamfarm Zoology Garden p. 222.

537 Parham JF, Feldman CR , Boore JL. 2006. The complete mitochondrial genome of the enigmatic 538 bigheaded turtle (Platysternon): description of unusual genomic features and the 539 reconciliation of phylogenetic hypotheses based on mitochondrial and nuclear DNA. BMC 540 Evolutionary Biology 6:1-11.

541 Pritchard PCH 1979. Encyclopaedia of Turtles. Neptune NJ : TFH Publications, Inc.

542 Rasmussen ARJ, Murphy C, Ompi M, Gibbons JW, Uetz P. 2011. Marine Reptiles. PLOS ONE 543 6(11):e27373.

544 Schumacher GH. 1973. The head muscles and hyolaryngeal skeleton of turtles and crocodilians.

545 In: Gans C, Parsons TS eds. Biology of Reptilia. USA:, New York: Academic Press. p. 101546199.

547 Schwenk K. 2000. Feeding: Form, Function and Evolution in tetrapod Vertebrates. San Diego548 San Francisco-New York-Boston-London-Sydney-Tokyo: Academic Press. 
549 Schwenk K, Wagner G. 2001. Function and the Evolution of Phenotypic Stability: Connecting $550 \quad$ Pattern to Process. American Zoologist 41:552-563.

551 Shaffer HB. 2009. Turtles (Testudines). Hedges SB, Kumar S eds. The Time Tree of Life. New 552 York, USA: Oxford University Press. p. 398-401.

553 Stanford CB, Wanchai P, Schaffer C, Schaffer R, Thirakhupt K. 2015. Manouria emys (Schlegel 554 and Müller 1840) - Asian Giant Tortoise, Giant Asian Forest Tortoise. In: Rhodin AGJ, 555 Pritchard PCH, van Dijk PP, Saumure RA, Buhlmann KA, Iverson JB, Mittermeier RA, eds. 556 Conservation Biology of Freshwater Turtles and Tortoises: A Compilation Project of the IUCN/SSC Tortoise and Freshwater Turtle Specialist Group. Chelonian Research Monographs (ISSN 1088-7105) No. 5, doi:10.3854/crm.5.086.emys.v1.2015

Stayton CT. 2011. Terrestrial feeding in aquatic turtles: environmentdependent feeding behavior, modulation and the evolution of terrestrial feeding in Emydidae. Journal of Experimental Biology 214:4083-4091.

Sterli J. 2010. Phylogenetic relationships among extinct and extant turtles: the position of Zoology 79:93-106.

565

566 Sterli J, de la Fuente MS. (2011). Re-description and evolutionary remarks on the Patagonian 567 horned turtle Niolamia argentina Ameghino, 1899 (Testudinata, Meiolaniidae). Journal of 568 Vertebrate Paleontology 31(6):1210-1229. 
569 Sukhanov VB. 2000. Mesozoic Turtles of Middle and Central Asia. In: Benton MJ, Shishkin

570 MA, Unwin DM, Kurochkin EN, eds. The Age of Dinosaurs in Russia and Mongolia.

571 Cambridge, UK: University Press. P. 309-367.

572 Summers AP, Darouian KF, Richmond AM, Brainerd EL. 1998. Kinematics of Aquatic and 573 Terrestrial Prey Capture in Terrapene carolina, With Implications for the Evolution of 574 Feeding in Cryptodire Turtles. Journal of Experimental Zoology 281:280-287

575 Thomson R C, Shaffer HB. 2010. Sparse supermatrices for phylogenetic inference: taxonomy, 576 alignment, rogue taxa, and the phylogeny of living turtles. Systematic Biology 59(1):42-58.

577 Vetter H, Daubner M. 2000. Das Schildkrötenlexikon auf CD. Bergheim: L. Staackmann Verlag $578 \quad$ KG.

579 Weisgram J. 1985a. Feeding mechanics of Claudius angustatus Cope 1865. In: Duncker HR, 580 Fleischer G, eds. Fortschritte der Zoologie. Stuttgart, Germany: Gustav Fischer Verlag. p. $581 \quad 257-260$.

582 Weisgram J. 1985b. Zum Mechanismus der Nahrungsaufnahme bei Schildkröten. Eine 583 vergleichend-funktionsanatomische Studie an Claudius angustatus COPE 1865, Pseudemys 584 scripta elegans WIED 1839 und Testudo hermanni hermanni GMELIN 1789. D. Phil. Thesis 585 Austria, Vienna: University of Vienna. $130 \mathrm{p}$.

586 Werneburg I. 2011. The cranial musculature in turtles. Palaeontologia Electronica 14(2):15a:99 587 pages.

588 Werneburg I. 2012. Temporal bone arrangements in turtles: an overview. Journal of 589 Experimental Zoology Part B: Molecular and Developmental Evolution 318: 235-249. 
590 Werneburg I. 2013. Jaw musculature during the dawn of turtle evolution. Organismal Diversity

$591 \quad$ and Evolution 13:225-254.

592 Werneburg I. 2014. Konvergente Evolution herbivorer Landwirbeltiere [ein Review]. In: Maier

593 W, Werneburg I (Eds.) "Schlüsselereignisse der organismischen Makroevolution". Scidinge $594 \quad$ Hall Verlag Zürich, p. 295-331.

595 Willis KL, Christensen-Dalsgaard J, Ketten DR, Carr CE. 2013. Middle ear cavity morphology is 596 consistent with an aquatic origin for Testudines. PLOS ONE 8(1):e54086.

597 Winokur RM, Legler JM. 1975. Chelonian mental glands. Journal of Morphology 147:275-291.

598 Winokur BM. 1988. The buccopharyngeal mucosa of the turtles (Testudines). J Morphol. $599 \quad 196: 33-52$.

600 Wochesländer R, Hilgers H, Weisgram J. 1999. Feeding Mechanism of Testudo hermanni 601 boettgeri ( Chelonia, Cryptodira). Netherland Journal of Zoology 49:1-13.

602 Wochesländer R, Gumpenberger M, Weisgram J. 2000. Intraoral food transport in Testudo 603 hermanni (Chelonia, Cryptodira) - a radiographic video analysis. Netherland Journal of $604 \quad$ Zoology 50:445-454.

605

606

607

608

609 
Figure 1 (on next page)

Figure 1

Phylogeny of turtle clades with a focus on Testudinoidea. Interrelationship following Thomson and Shaffer (2010). Major evolutionary changes are listed; for details see text. Three modes of terrestrial food uptake are illustrated. A) Jaw prehension; the tongue is not protruded and is only used for food transport (Geoemydida, Manouria). B) Jaw prehension; the elongated tongue is protruded during prehension but does not contact the food and is only used for food transport (Emydidae). C) Prior to jaw prehension, the tongue contacts the food (advanced tortoises). 


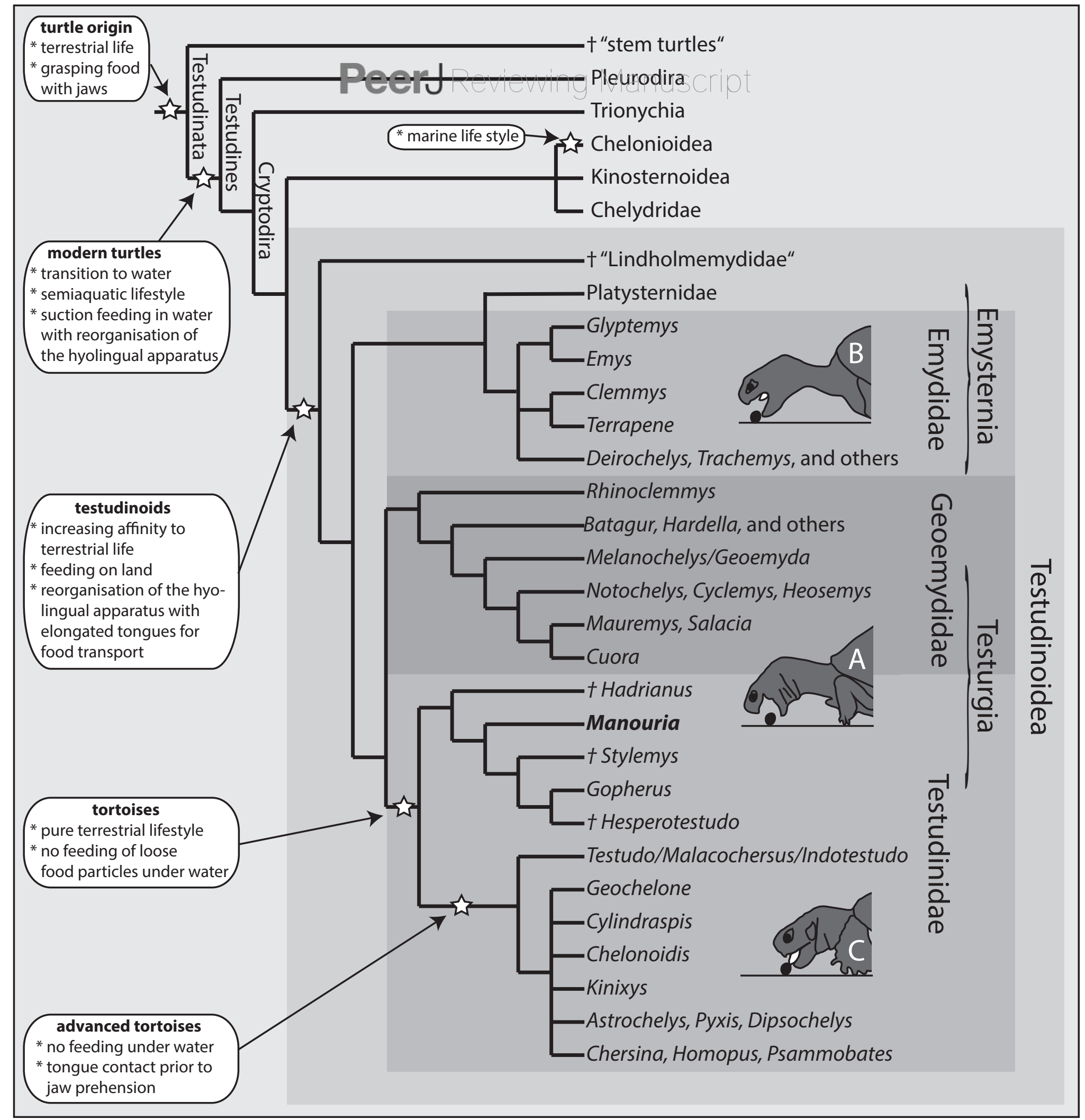


2

Figure 2

Selected frame from a high-speed video sequence (500 frs) of food transport in Manouria emys, showing the landmarks used for kinematic analyses: $\mathrm{C}$, rostral tip of sagital line of the carapace, Hy, hyoid at the basis of ceratbranchial I; LJ, tip of the lower jaw; P, posterior most point of crista supraoccipitale; $T$, tip of the tongue; $T v$, ventral most point of the tympanum at the position of the jaw joint; UJ, tip of the upper jaw; grid 10x10 mm. Abbreviations in Appendix 1. 


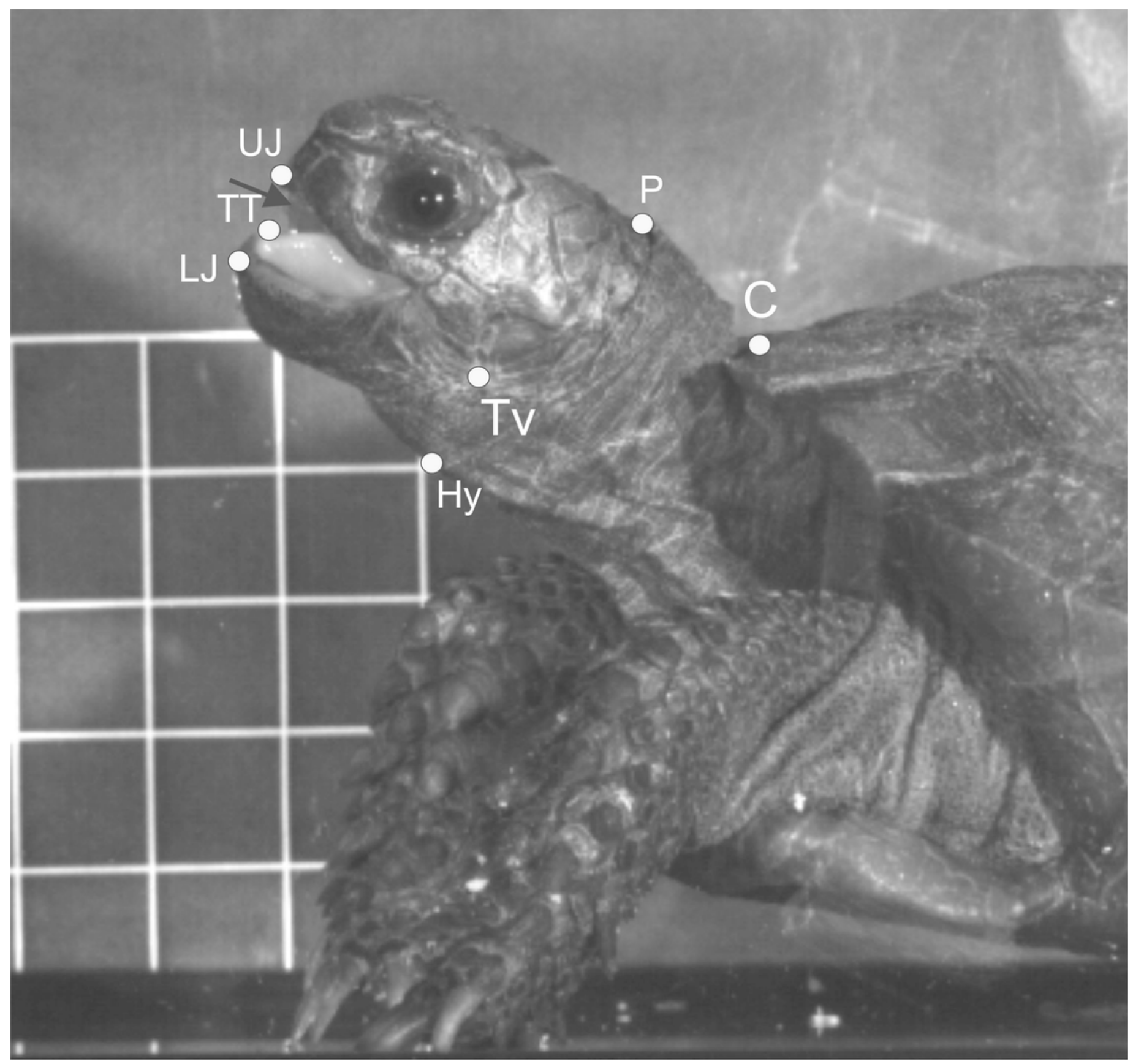




\section{3}

Figure 3

Selected frames and graphics (based on a high-speed video with $500 \mathrm{frs}$ ) represent the movements of jaws, hyoid and thead during terrestrial food uptake in Manouria emys when feeding on pieces of beef heart; a, slow open phase end (lacking discrete SOI and SOII); b, fast open end; $c$, fast close start; $d$, fast close end; arrows indicate the position of the food item; arrowheads represent the position of the tip of the tongue; grid $10 \times 10 \mathrm{~mm}$. Abbreviations in Appendix 1. 

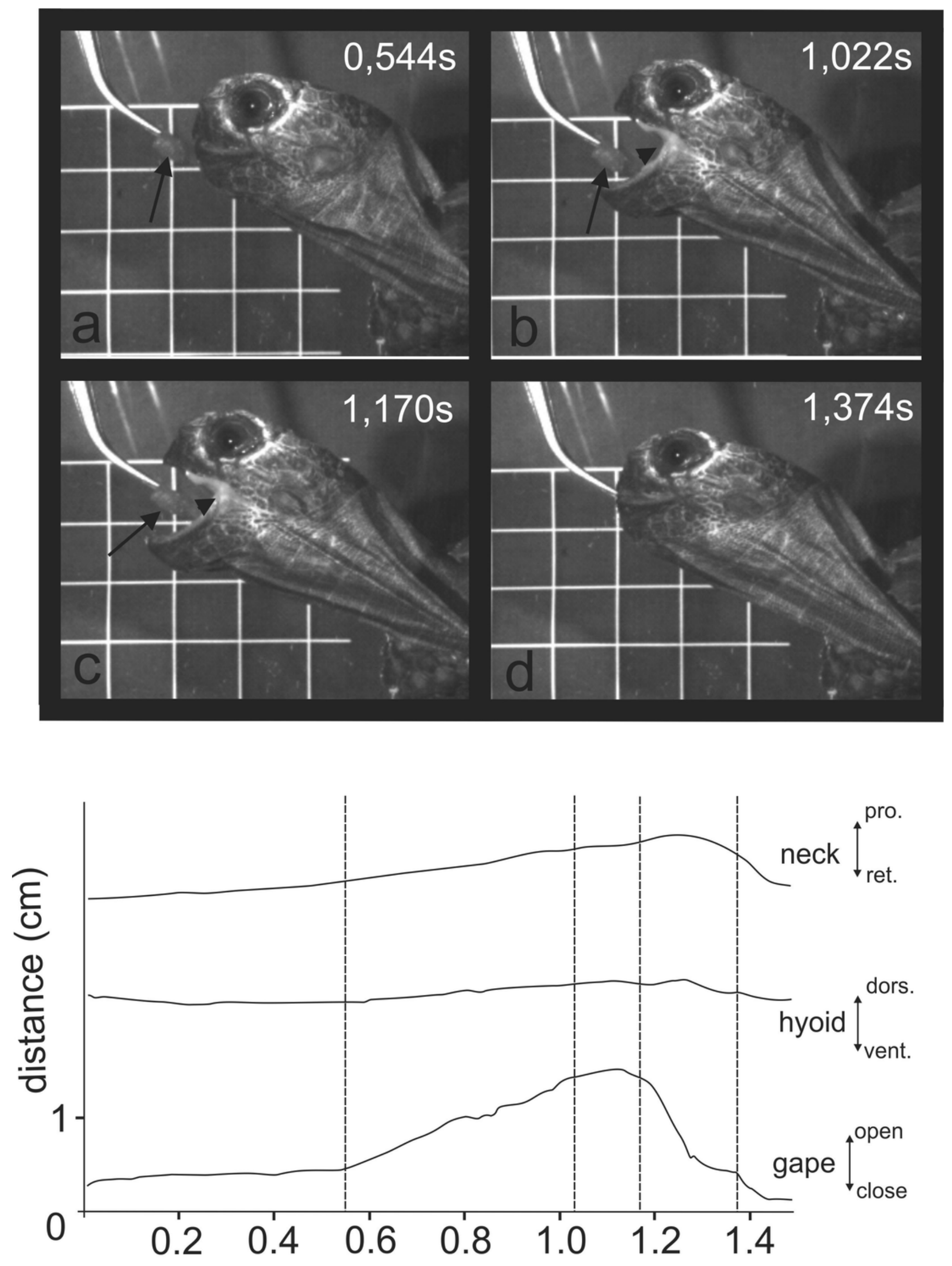

Peerj reviewing PPF (2015:03:4273:2:0:NEW 24 Jun 2015)

time (s) 


\section{4}

Figure 4

Selected frames and graphics (based on high-speed video with $250 \mathrm{frs}$ ) showing the movements of jaws, hyoid, and head during attempts of aquatic food uptake in Manouria emys; $a$, start of the gape cycle; $b$, end of jaw opening; c, maximum gape end; $d$, fast closure end; note the lack of movement of the hyoid complex during the whole cycle; grid 10x10 $\mathrm{mm}$. Abbreviations in Appendix 1. 

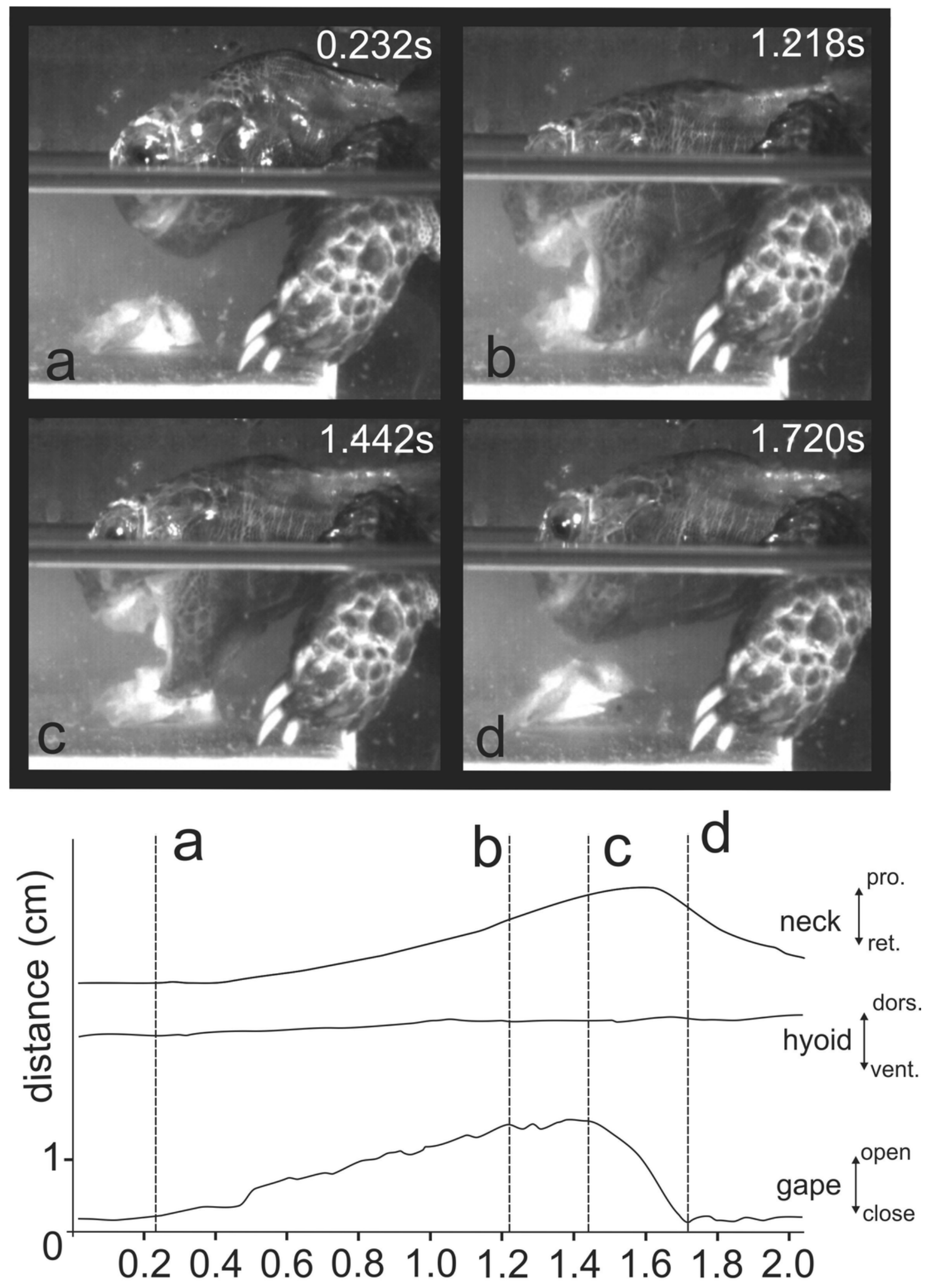

PeerJ reviewinqPDF (2015:03:4273:2:0:NEW 24 Jun 2015) time (s) 


\section{5}

Figure 5

Selected graphics (based on a high-speed video with $500 \mathrm{fr} / \mathrm{s}$ ) showing the movement patterns of jaws, hyoid, tongue and head during terrestrial food transport in M. emys; note the delay in hyoid ventral displacement relative to the start the retraction of the tongue tip, as well as the delay of both the tongue retraction and hyoid retraction relative to the start of the FO phase. Abbreviations in Appendix 1. 


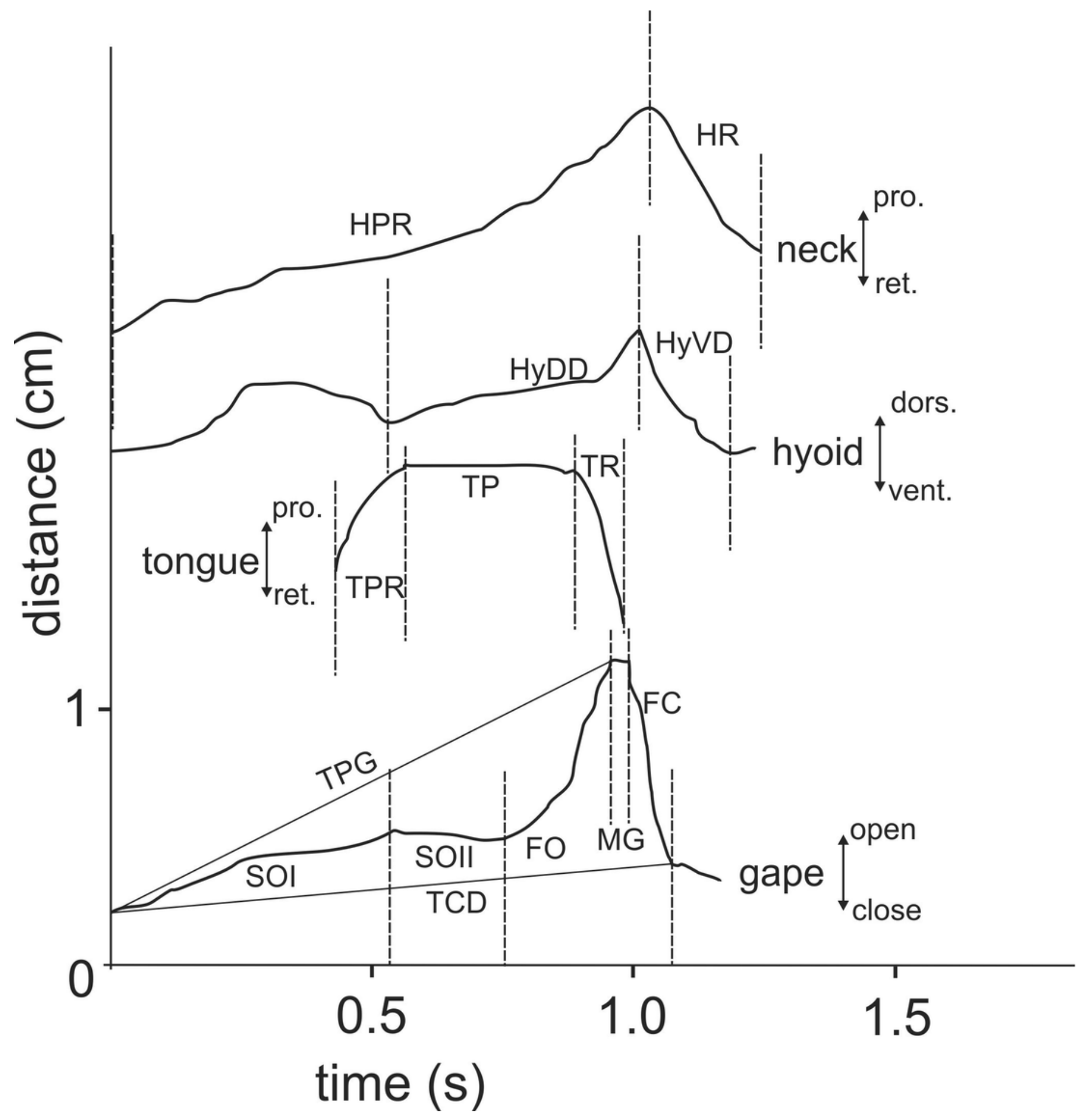


6

Figure 6

Graphical representation of three selected variables in food uptake (FU) and food transport

(T) phases. Bars are denoted by their mean values and whiskers present the $95 \% \mathrm{Cl}$; $\mathrm{A}$, sequences with discrete SO and FO phases; B, sequences with no detectable split of discrete slow gape phase (SOI and SOII were inseparable); C - sequences with lacking MG phase. Abbreviations in Appendix 1. 


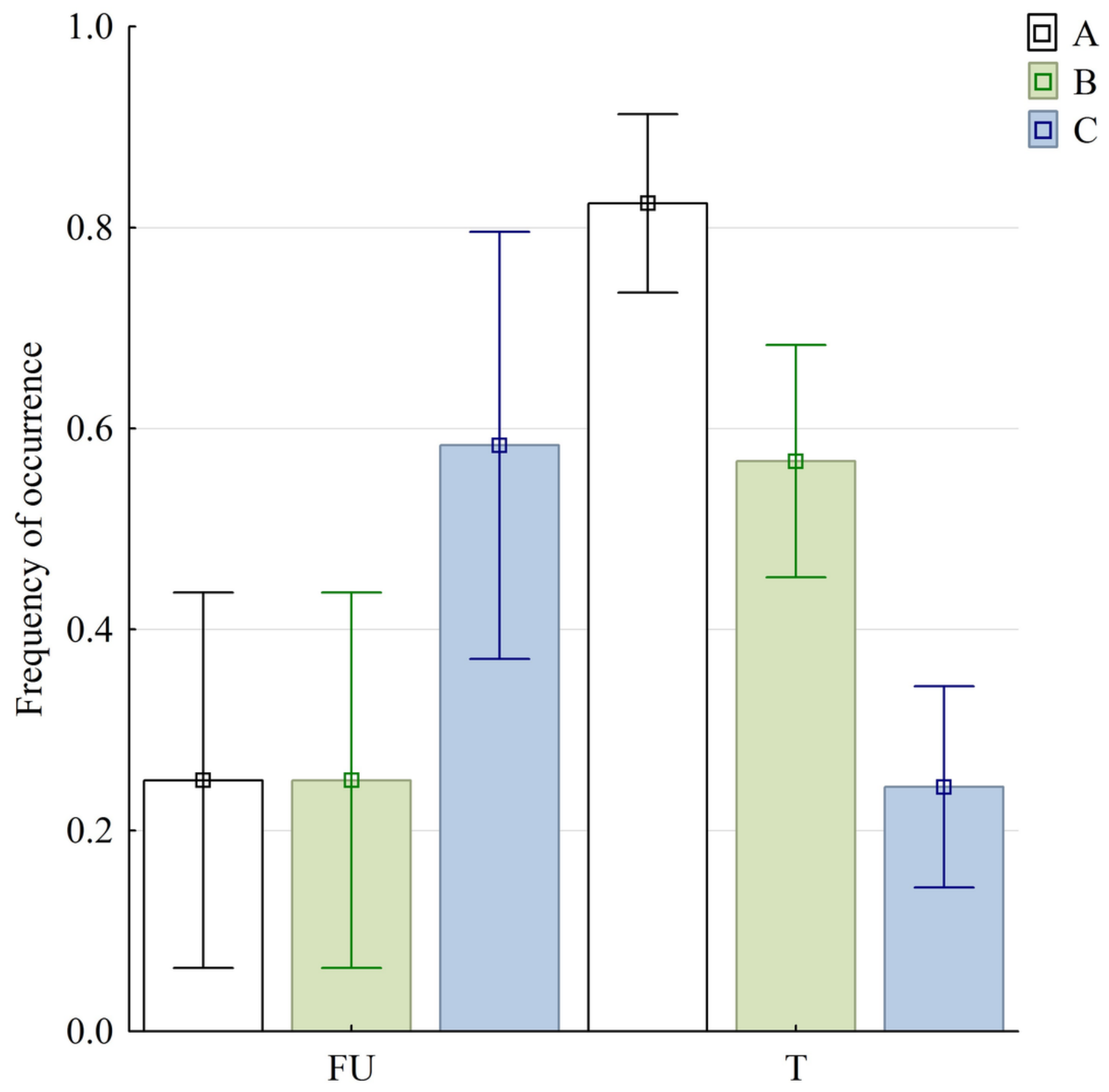


7

Figure 7

Canonical centroid plots of three Manouria emys specimens (T1-T3), centroid scores for each individual and measurement repetition in food transport phase.

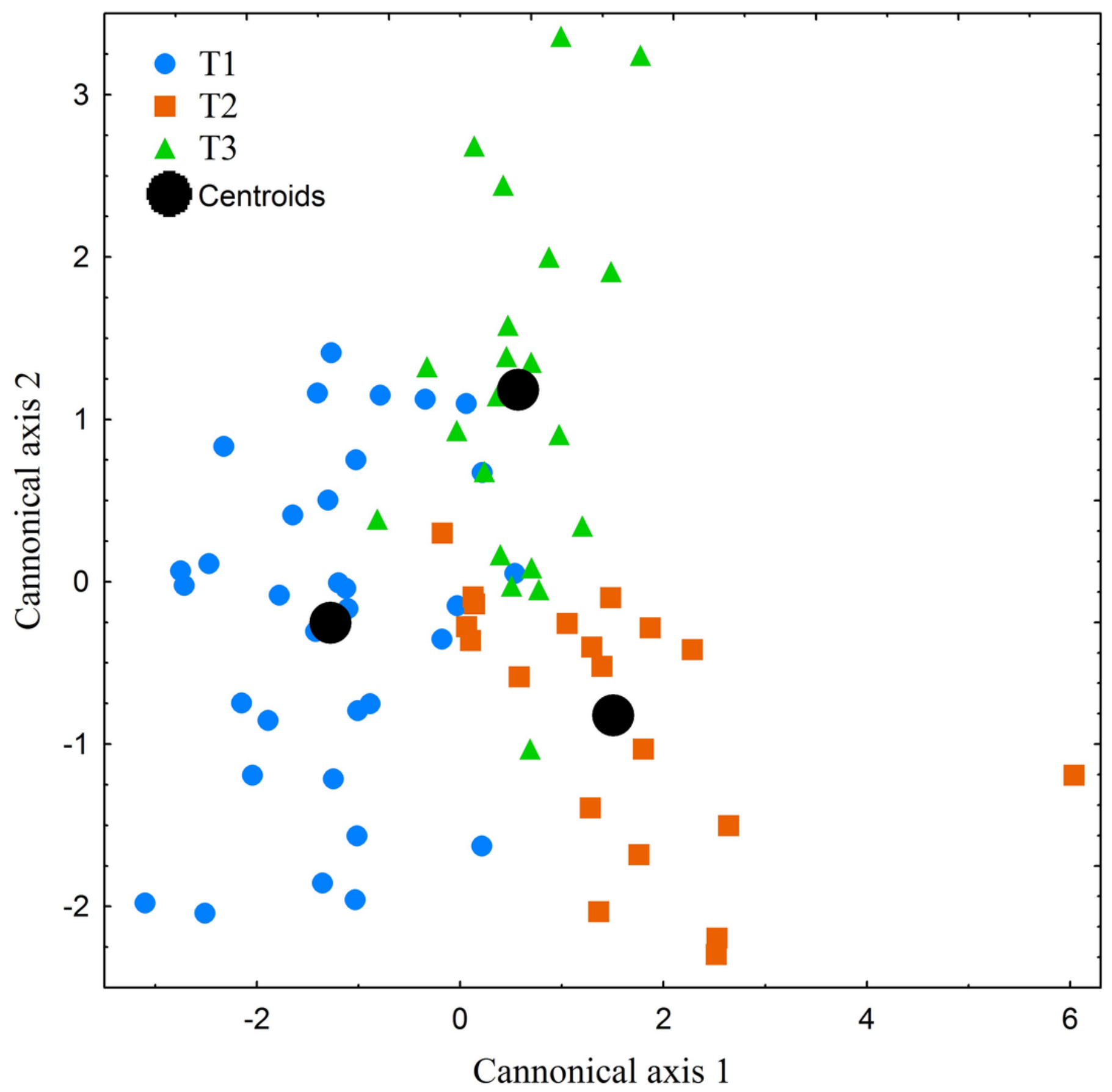




\section{Table $\mathbf{1}$ (on next page)}

Table 1

Variables describing the feeding process in Manouria emys, present as means $\pm S D ; n$, sample size; *, significant differences $(\alpha=0.05)$ among individuals in the ingestion phase (P1), in the transport phase (P2), and between both mode (P3); n.c., p value not calculated. Abbreviations in appendix 1. 
1

Food uptake (FU)

Transport (T)

I vs. T

\begin{tabular}{|c|c|c|c|c|c|c|c|c|c|}
\hline & & & & & & & & & \\
\hline Variable & $\begin{array}{c}\text { individual } 1 \\
(\mathrm{n}=8)\end{array}$ & $\begin{array}{c}\text { individual } 2 \\
(\mathrm{n}=8)\end{array}$ & $\begin{array}{c}\text { individual } 3 \\
(\mathrm{n}=8)\end{array}$ & p1 & $\begin{array}{c}\text { individual } 1 \\
(\mathrm{n}=33)\end{array}$ & $\begin{array}{c}\text { individual } 2 \\
(\mathrm{n}=20)\end{array}$ & $\begin{array}{c}\text { individual } 3 \\
(\mathrm{n}=21)\end{array}$ & $\mathrm{p} 2$ & p3 \\
\hline SOI duration $[\mathrm{s}]$ & $\begin{array}{c}0.168 \pm 0.060 \\
n=2\end{array}$ & $\begin{array}{c}0.618 \pm 0.231 \\
n=3\end{array}$ & $\begin{array}{c}0,562 \\
n=1\end{array}$ & n.c. & $\begin{array}{c}0.146 \pm 0.016 \\
n=18\end{array}$ & $\begin{array}{c}0.126 \pm 0.014 \\
n=14\end{array}$ & $\begin{array}{c}0.115 \pm 0.015 \\
\mathrm{n}=11\end{array}$ & 0,378 & 0,068 \\
\hline SOII duration $[\mathrm{s}]$ & $\begin{array}{c}0.738 \pm 0.508 \\
\mathrm{n}=2\end{array}$ & $\begin{array}{c}0.453 \pm 0.294 \\
\mathrm{n}=3\end{array}$ & $\begin{array}{c}1,024 \\
n=1\end{array}$ & n.c. & $\begin{array}{c}0.147 \pm 0.014 \\
\mathrm{n}=18\end{array}$ & $\begin{array}{c}0.187 \pm 0.027 \\
\mathrm{n}=13\end{array}$ & $\begin{array}{c}0.190 \pm 0.021 \\
\mathrm{n}=11\end{array}$ & 0,187 & 0,072 \\
\hline FO duration $[\mathrm{s}]$ & $\begin{array}{c}0.450 \pm 0.060 \\
\mathrm{n}=2\end{array}$ & $\begin{array}{c}0.379 \pm 0.150 \\
\mathrm{n}=3\end{array}$ & $\begin{array}{c}0,694 \\
n=1\end{array}$ & n.c. & $\begin{array}{c}0.122 \pm 0.009 \\
\mathrm{n}=25\end{array}$ & $\begin{array}{c}0.126 \pm 0.012 \\
\mathrm{n}=15\end{array}$ & $\begin{array}{c}0.102 \pm 0.006 \\
\mathrm{n}=19\end{array}$ & 0,111 & $0.011 *$ \\
\hline MG duration $[\mathrm{s}]$ & $\begin{array}{c}0.079 \pm 0.017 \\
\mathrm{n}=4\end{array}$ & $\begin{array}{c}0.095 \pm 0.031 \\
\mathrm{n}=4\end{array}$ & $\begin{array}{c}0.166 \pm 0.044 \\
n=6\end{array}$ & 0,271 & $\begin{array}{c}0.025 \pm 0.003 \\
\mathrm{n}=6\end{array}$ & $\begin{array}{c}0.033 \pm 0.004 \\
\mathrm{n}=10\end{array}$ & $\begin{array}{c}0.042 \pm 0.019 \\
\mathrm{n}=4\end{array}$ & 0,318 & $0.001 *$ \\
\hline FC duration $[\mathrm{s}]$ & $\begin{array}{c}0.157 \pm 0.079 \\
\mathrm{n}=8\end{array}$ & $\begin{array}{c}0.105 \pm 0.036 \\
\mathrm{n}=8\end{array}$ & $\begin{array}{c}0.158 \pm 0.030 \\
\mathrm{n}=8\end{array}$ & $0.024 *$ & $\begin{array}{c}0.089 \pm 0.020 \\
\mathrm{n}=33\end{array}$ & $\begin{array}{c}0.186 \pm 0.040 \\
\mathrm{n}=20\end{array}$ & $\begin{array}{c}0.119 \pm 0.088 \\
\mathrm{n}=21\end{array}$ & 0,155 & $0.010^{*}$ \\
\hline TPG $[\mathrm{s}]$ & $\begin{array}{c}0.943 \pm 0.144 \\
\mathrm{n}=8\end{array}$ & $\begin{array}{c}0.989 \pm 0.177 \\
\mathrm{n}=8\end{array}$ & $\begin{array}{c}1.784 \pm 0.137 \\
\mathrm{n}=8\end{array}$ & $0.002 *$ & $\begin{array}{c}0.408 \pm 0.021 \\
\mathrm{n}=33\end{array}$ & $\begin{array}{c}0.439 \pm 0.038 \\
\mathrm{n}=20\end{array}$ & $\begin{array}{c}0.403 \pm 0.028 \\
\mathrm{n}=21\end{array}$ & 0,187 & $<0.001^{*}$ \\
\hline TCD duration $[\mathrm{s}]$ & $\begin{array}{c}1.139 \pm 0.148 \\
\mathrm{n}=8\end{array}$ & $\begin{array}{c}1.128 \pm 0.169 \\
\mathrm{n}=8\end{array}$ & $\begin{array}{c}2.073 \pm 0.144 \\
\mathrm{n}=8\end{array}$ & $0.001 *$ & $\begin{array}{c}0.499 \pm 0.020 \\
\mathrm{n}=33\end{array}$ & $\begin{array}{c}0.655 \pm 0.098 \\
\mathrm{n}=20\end{array}$ & $\begin{array}{c}0.510 \pm 0.030 \\
\mathrm{n}=21\end{array}$ & 0,311 & $<0.001^{*}$ \\
\hline HDD duration [s] & & & & & $\begin{array}{c}0.281 \pm 0.025 \\
\mathrm{n}=30\end{array}$ & $\begin{array}{c}0.216 \pm 0.035 \\
\mathrm{n}=14\end{array}$ & $\begin{array}{c}0.169 \pm 0.019 \\
\mathrm{n}=21\end{array}$ & $0.005^{*}$ & \\
\hline HVD duration [s] & & & & & $\begin{array}{c}0.176 \pm 0.011 \\
\mathrm{n}=31\end{array}$ & $\begin{array}{c}0.167 \pm 0.014 \\
\mathrm{n}=17\end{array}$ & $\begin{array}{c}0.149 \pm 0.009 \\
\mathrm{n}=21\end{array}$ & 0,162 & \\
\hline THC duration $[\mathrm{s}]$ & & & & & $\begin{array}{c}0.456 \pm 0.028 \\
\mathrm{n}=30\end{array}$ & $\begin{array}{c}0.384 \pm 0.041 \\
\mathrm{n}=14\end{array}$ & $\begin{array}{c}0.317 \pm 0.022 \\
\mathrm{n}=21\end{array}$ & $0.002 *$ & \\
\hline $\begin{array}{l}\text { HRV velocity } \\
{[\mathrm{cm} / \mathrm{s}]}\end{array}$ & & & & & $\begin{array}{c}0.718 \pm 0.059 \\
\mathrm{n}=31\end{array}$ & $\begin{array}{c}0.938 \pm 0.107 \\
\mathrm{n}=17\end{array}$ & $\begin{array}{c}0.551 \pm 0.071 \\
\mathrm{n}=21\end{array}$ & $0.016^{*}$ & \\
\hline HP duration [s] & $\begin{array}{c}1.345 \pm 0.159 \\
\mathrm{n}=8\end{array}$ & $\begin{array}{c}1.204 \pm 0.246 \\
\mathrm{n}=8\end{array}$ & $\begin{array}{c}2.494 \pm 0.177 \\
\mathrm{n}=8\end{array}$ & $0.001 *$ & $\begin{array}{c}0.220 \pm 0.049 \\
\mathrm{n}=32\end{array}$ & $\begin{array}{c}0.864 \pm 0.132 \\
\mathrm{n}=14\end{array}$ & $\begin{array}{c}0.464 \pm 0.089 \\
\mathrm{n}=10\end{array}$ & $0.001^{*}$ & $<0.001 *$ \\
\hline HR duration $[\mathrm{s}]$ & $\begin{array}{c}0.296 \pm 0.041 \\
n=8\end{array}$ & $\begin{array}{c}0.487 \pm 0.086 \\
n=7\end{array}$ & $\begin{array}{c}0.704 \pm 0.174 \\
n=8\end{array}$ & 0,052 & $\begin{array}{c}0.236 \pm 0.027 \\
n=14\end{array}$ & $\begin{array}{c}0.211 \pm 0.025 \\
n=13\end{array}$ & $\begin{array}{c}0.316 \pm 0.065 \\
n=10\end{array}$ & 0,333 & $0.002 *$ \\
\hline TP duration [s] & & & & & $\begin{array}{c}0.165 \pm 0.008 \\
n=30\end{array}$ & $\begin{array}{c}0.160 \pm 0.017 \\
n=19\end{array}$ & $\begin{array}{c}0.133 \pm 0.025 \\
n=13\end{array}$ & 0,483 & \\
\hline $\begin{array}{c}\text { TR velocity } \\
{[\mathrm{cm} / \mathrm{s}]}\end{array}$ & & & & & $\begin{array}{c}7.459 \pm 0.550 \\
\mathrm{n}=31\end{array}$ & $\begin{array}{c}5.798 \pm 0.547 \\
\mathrm{n}=20\end{array}$ & $\begin{array}{c}6.562 \pm 0.595 \\
\mathrm{n}=13\end{array}$ & 0,121 & \\
\hline $\begin{array}{l}\text { delay of HVD } \\
\text { start relative to }\end{array}$ & & & & & & & & & \\
\hline TR start [s] & & & & & $\begin{array}{c}-0.2011 \pm 0.026 \\
\mathrm{n}=30\end{array}$ & $\begin{array}{c}-0.039 \pm 0.231 \\
n=15\end{array}$ & $\begin{array}{c}-0.082 \pm 0.025 \\
\mathrm{n}=14\end{array}$ & $0.005^{*}$ & \\
\hline $\begin{array}{l}\text { delay of TPG } \\
\text { relative to HVD }\end{array}$ & & & & & & & & & \\
\hline start [s] & & & & & $\begin{array}{c}-0.007 \pm 0.007 \\
\mathrm{n}=31\end{array}$ & $\begin{array}{c}-0.016 \pm 0.008 \\
\mathrm{n}=17\end{array}$ & $\begin{array}{c}-0.032 \pm 0.005 \\
\mathrm{n}=21\end{array}$ & $0.014 *$ & \\
\hline $\begin{array}{l}\text { delay of TPG } \\
\text { relative to TR }\end{array}$ & & & & & & & & & \\
\hline $\begin{array}{c}\text { start }[\mathrm{s}] \\
2\end{array}$ & & & & & $\begin{array}{c}-0.062 \pm 0.007 \\
\mathrm{n}=31\end{array}$ & $\begin{array}{c}-0.045 \pm 0.013 \\
n=20\end{array}$ & $\begin{array}{c}-0.055 \pm 0.008 \\
n=14\end{array}$ & 0,521 & \\
\hline
\end{tabular}

